\title{
Performance and Adaptive Surge-Preventing Acceleration Prediction of a Turboshaft Engine under Inlet Flow Distortion
}

\author{
Dalu Cao , Hailong Tang and Min Chen \\ Beihang University, Xueyuan Road No. 37, Haidian District, Beijing, China
}

\begin{abstract}
The intention of this paper is to research the inlet flow distortion influence on overall performance of turboshaft engine and put forward a method called Distortion Factor Item (DFI) to improve the fuel supply plan for surge-preventing acceleration when turboshaft engine suddenly encounters inlet flow distortion. Based on the parallel compressor theory, steady-state and transition-state numerical simulation model of turboshaft engine with subcompressor model were established for researching the influence of inlet flow distortion on turboshaft engine. This paper made a detailed analysis on the compressor operation from the aspects of performance and stability, and then analyzed the overall performance and dynamic response of the whole engine under inlet flow distortion. Improved fuel supply plan with DFI method was applied to control the acceleration process adaptively when encountering different inlet flow distortion. Several simulation examples about extreme natural environments were calculated to testify DFI method's environmental applicability. The result shows that the inlet flow distortion reduces the air inflow and decreases the surge margin of compressor, and increase the engine exhaust loss. Encountering inlet flow distortion has many adverse influences such as sudden rotor acceleration, turbine inlet temperature rise and power output reduction. By using improved fuel supply plan with DFI, turboshaft engine above-idle acceleration can avoid surge effectively under inlet flow distortion with environmental applicability.
\end{abstract}

\section{Introduction}

Helicopters often encounter inlet flow distortion in flight. Inlet flow distortion can be caused by many sources such as crosswind-induced inlet separation, armament firing, and shock-boundary layer interaction in a supersonic inlet. Whatever the source, the performance and stability of the aeroengine generally reduced. Even the blade rupture fault occurred when the compressor surged caused by inlet flow distortion [1].

Previously, scholars have researched inlet flow distortion by using computational fluid dynamics (CFD) methods or experiments that concentrated on flow field analysis and distortion transfer in compressor. Chen [2] found the inlet flow distortion deteriorated the pressure ratio, flow range, and efficiency of the compressor. Yao [3-4] explained how the total temperature distortion phasing was generated and phase changes as the distortion transfers in the fan model. Sitaram [5] found that the circumferential distortion had more effect than the radial distortion on the mass averaged flow parameters. However, little research has been devoted to the influence of inlet flow distortion on the overall performance from the perspective of the whole aeroengine.

High Stability Engine Control (HISTEC) program [6] researched by NASA was to design, develop, and flight demonstrate an advanced, high-stability, integrated engine control system that uses measurement-based, real-time estimation of distortion to enhance engine stability. HISTEC installed on the F-15 Advanced Control Technology for Integrated Vehicles aircraft at NASA Dryden and the HISTEC technologies were successfully flight demonstrated. It indicated that inlet flow distortion parameters can be accurately estimated real-time in the future. The research of this paper is based on the assumption that the distorted inflow thermal parameters can be estimated.

Figure 1 shows that transition-state working line is closer to the surge boundary during acceleration process. It indicates that compressor surge margin is lower during the acceleration so that compressor surge is more likely to occur.

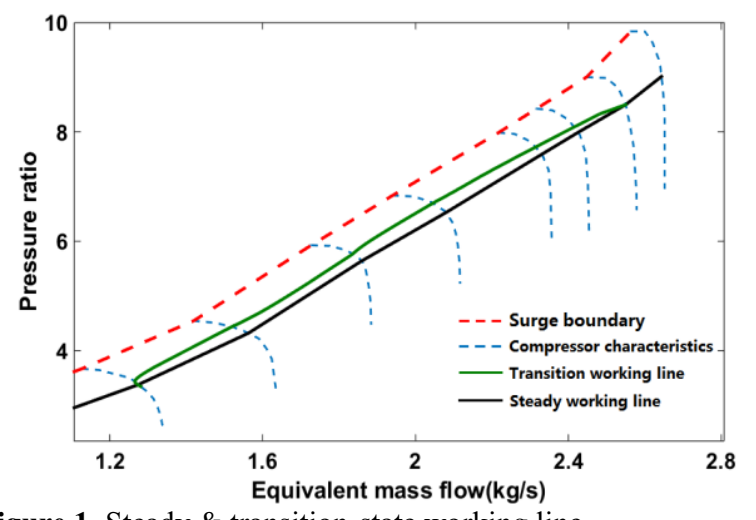

Figure 1. Steady \& transition-state working line 
Inlet flow distortion can be classified in various ways such as from the aspect of thermal parameters or spatial distribution. Due to the high radial gradient of pressure and temperature in compressor blade path, the flow mix more easily in radial direction so that the radial distortion is weakened obviously. Figure 2 shows the inlet flow distortion model that was researched in this paper. It is the simplest form of circumferential distortion, including both steady-state and dynamic-state.

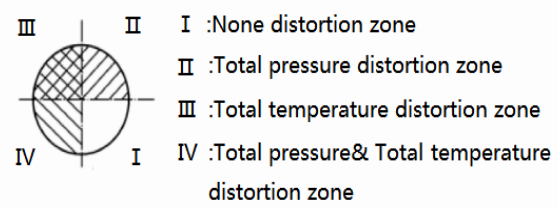

Figure 2. Division of circumferential inlet flow distortion

This paper is mainly divided into three major sections:

1) Section one introduced the modeling of turboshaft engine and sub-compressor.

2) Section two analyzed the influences of inlet flow distortion on the overall performance from the perspective of the whole turboshaft engine..

3) Section three presented the DFI method to improve fuel supply plan for surge-preventing acceleration and testified its environmental applicability.

\section{Model development}

Figure 3 shows the structure diagram of turboshaft engine. Based on a real turboshaft engine in service, the model was developed in Matlab/Simulink platform with the following characteristics [7]:

1) Physics based (e.g., thermodynamic, inertia, etc.)

2) Modular/component based construction.

3) Incorporating engine dimensions and component maps for sizing.

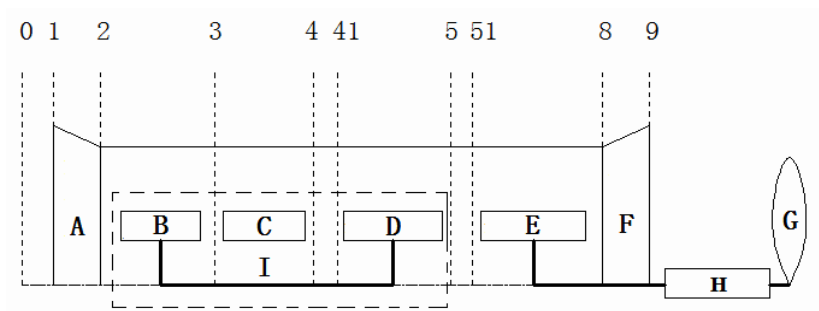

A:In1et B:Compressor C:Combustor D:Gas Turbine

E:Power Turbine F:Exhaust G:Gear Box H:Rotor Wing

I:Gas generator

Figure 3. Simple layout of the turboshaft engine

\subsection{Steady-state modeling}

Figure 4 shows the Steady-state simulink model. Steadystate operation of the engine was described by Steadystate working equations, which were based on flow continuity of each components and rotor power balance. Physical speed of the gas generator $(\mathrm{N})$ and power turbine $(\mathrm{Np})$ were the control parameters in the steady-state control strategy.

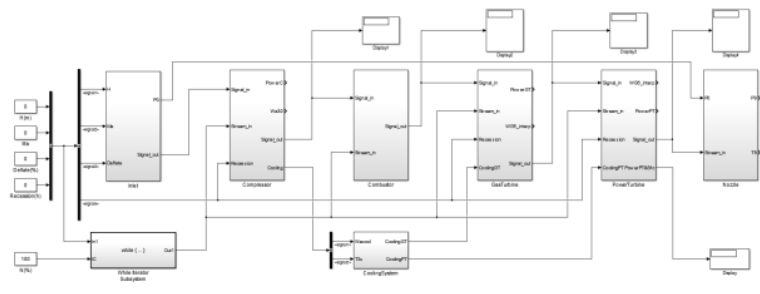

Figure 4. Steady-state simulink model

Four balance equations were used to described the steady-state operation.

1) Gas turbine flow continuity equation.

$$
W_{3}+W_{G T, \text { Cooling }}+W_{f}-W_{5}=0
$$

where $W$ is mass flow; subscript GT,Cooling is Gas turbine cooling air from compressor.

2) Power turbine flow continuity equation.

$$
W_{5}+W_{P T, \text { Cooling }}-W_{6}=0
$$

where subscript $P T$, Cooling is power turbine cooling air from compressor.

3) Nozzle outlet static pressure balance equation.

$$
P s_{9}-P s_{a m b}=0
$$

where $P s$ is static pressure; subscript $a m b$ is

4) Gas generator power balance equation.

$$
P_{\mathrm{GT}} \eta_{G T}-P_{\text {Compr }}-P_{E X T}=0
$$

where $P$ is power; $\eta$ is mechanical efficiency; subscript $G T$ is gas turbine; subscript Compr is Compressor; subscript $E X T$ is power extraction.

While in simulation calculation, the balance equations aren't strictly valid because the residuals of each balance equation always exist.

$$
\begin{gathered}
z_{1}=W_{3}+W_{G T, \text { Cooling }}+W_{f}-W_{5} \\
z_{2}=W_{5}+W_{P T, \text { Cooling }}-W_{6} \\
z_{3}=P_{s 9}-P_{a m b} \\
z_{4}=P_{\mathrm{GT}} \eta_{G T}-P_{C o m p r}-P_{E X T}
\end{gathered}
$$

If the residuals are sufficiently small, the balance equations could be valid approximately. To ensure the equations have the sole solution, four unknowns are needed, as shown in Table 1 .

Table 1. Unknowns for balance equations

\begin{tabular}{|c|c|c|}
\hline Unknow & $\begin{array}{c}\text { Corrresponding } \\
\text { variable }\end{array}$ & Meaning \\
\hline $\mathrm{x}_{1}$ & $\mathrm{Z}_{\mathrm{C}}$ & Compr Auxiliary line value \\
\hline $\mathrm{x}_{2}$ & $\mathrm{Z}_{\mathrm{HPT}}$ & GT conversion power \\
\hline $\mathrm{x}_{3}$ & $\mathrm{Z}_{\mathrm{LPT}}$ & PT conversion power \\
\hline $\mathrm{x}_{4}$ & $\mathrm{Wf}_{\mathrm{R}}$ & Relative fuel flow \\
\hline
\end{tabular}

The residual vector $Z=\left[\begin{array}{ll}z 1, & z 2, z 3, z 4\end{array}\right]^{T}$ and the unknows vector $\mathrm{X}=\left[\begin{array}{llll}\mathrm{x}_{1}, & \mathrm{x}_{2}, & \mathrm{x}_{3}, & \mathrm{x}_{4}\end{array}\right]^{\mathrm{T}}$ were defined. 
Obviously, $\mathrm{Z}=\mathrm{F}(\mathrm{X})$ and is calculated by thermodynamic calculation along the engine path. The balance equations solution algorithm is as follows: Assuming that $\mathrm{k}$ iterations have been made so that now $X^{(\mathrm{k})}=\left[\mathrm{x}_{1}{ }^{(\mathrm{k})}, \mathrm{x}_{2}{ }^{(\mathrm{k})}\right.$,

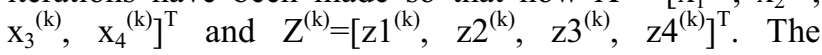
Newton-Raphson method is used to make Z's norm approach to zero. In the next iteration, $\mathrm{X}$ is updated by $\mathrm{A}$ (Jacobi matrix) and Z.

$$
\begin{gathered}
X^{(k+1)}=X^{(k)}-A^{-1} Z^{(k)} \\
A=\left[\begin{array}{ccc}
\frac{\partial z_{1}}{\partial x_{1}} & \cdots & \frac{\partial z_{1}}{\partial x_{4}} \\
\vdots & \ddots & \vdots \\
\frac{\partial z_{4}}{\partial x_{1}} & \cdots & \frac{\partial z_{4}}{\partial x_{4}}
\end{array}\right]
\end{gathered}
$$

If Z's norm meet the given accuracy requirement, the iteration would be ended and output $\mathrm{X}$ to accomplish the final thermodynamic calculation and output turboshaft engine performance calculation result. Figure 5 shows the algorithm flow chart of the steady-state calculation.

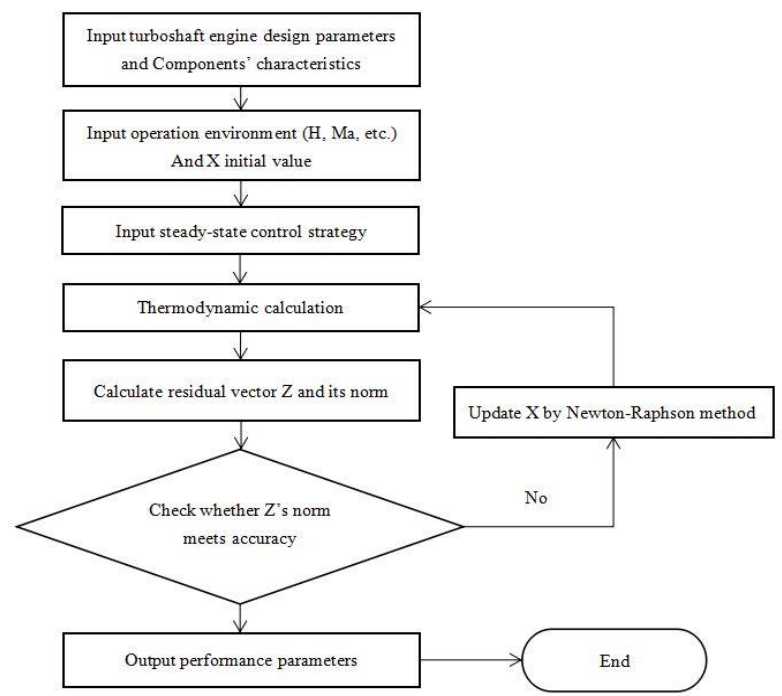

Figure 5. Algorithm of steady-state calculation

\subsection{Transition-state modeling}

Figure 6 shows the transition-state simulink model. In this model, the balance equation (1), (2) and (3) were still valid, while the balance equation (4) was not. Relative physical speed of power turbine (Np) and fuel supply (Wf) were the control parameters in the transition-state control strategy.

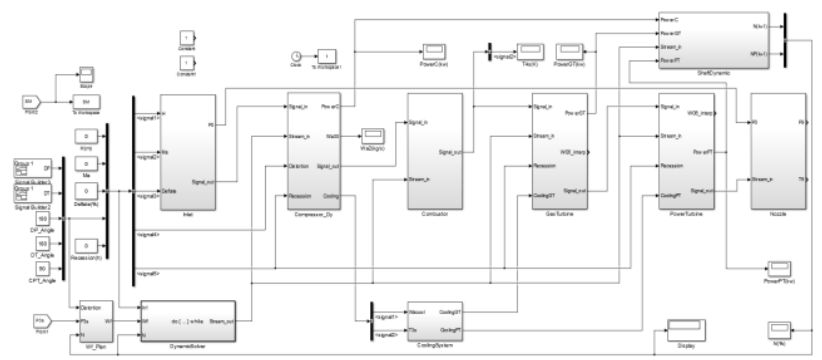

Figure 6. Transition-state simulink model
Unlike steady-state gas generator power balance equation, the inertia and dynamic characteristics of rotor was taken into consideration to describe the engine transition-state operation. The rotor motion was described by differential equations that solved by Euler method in fixed step size calculation.

$$
P_{\mathrm{GT}} \eta_{G T}-P_{\text {Compr }}-P_{E X T}-\left(\frac{\pi}{30}\right)^{2} J N \frac{d N}{d t}=0
$$

Figure 7 shows the algorithm flow chart of the transition-state calculation.

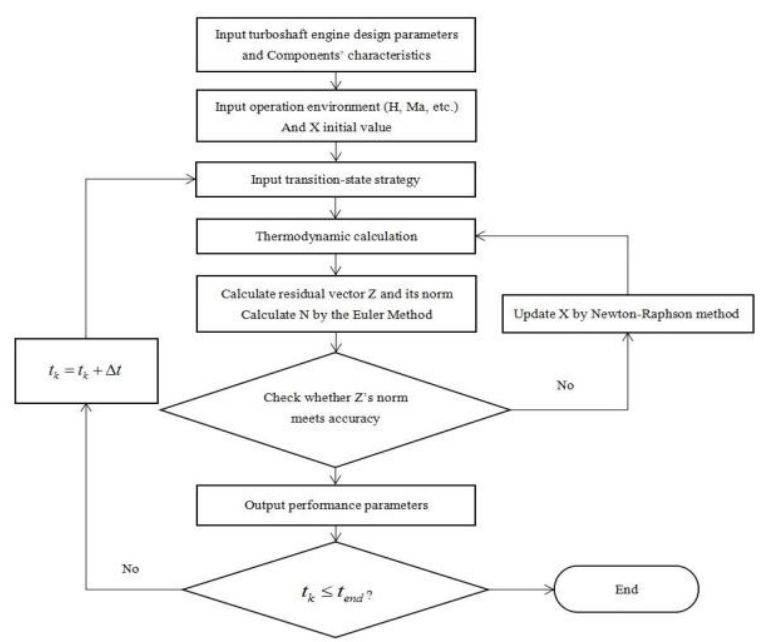

Figure 7. Algorithm of transition-state calculation

\subsection{Inlet flow distortion parameters definition}

1) Distortion level coefficient

DP and DT represent the level of total pressure and total temperature distortion respectively [8] whose definition are shown in the formula (12) and formula (13).

$$
\begin{aligned}
& D P=\frac{P_{\text {distorton }}^{*}-P_{\text {none_distorton }}^{*}}{P_{\text {none_distorton }}^{*}} \times 100 \% \\
& D T=\frac{T_{\text {distorton }}^{*}-T_{\text {none_distorton }}^{*}}{T_{n o n e \_d i s t o r t o n}^{*}} \times 100 \%
\end{aligned}
$$

2) Distortion sector angle

$\theta_{\mathrm{DT}}, \theta_{\mathrm{DP}}$ and $\theta_{\mathrm{DPT}}$ represent the circumferential distribution of each distortion zone.

\subsection{Sub-compressor modeling}

The parallel compressor theory [8] can accurately explain the essence of inlet flow distortion and analyze its influence on the performance and stability of aeroengine. Its validity and accuracy have already been proved by experiments [9].

Figure 8 shows the algorithm flow chart of subcompressor and its essential characteristics are shown as follow:

1) Internal flow in the sub-compressor is uniform.

2) No mass, momentum and energy exchange between sub-compressors. 
3) The flow static pressure of each sub-compressor outlet is equal.

4) If any sub-compressor occurs surge, the compressor occurs surge.

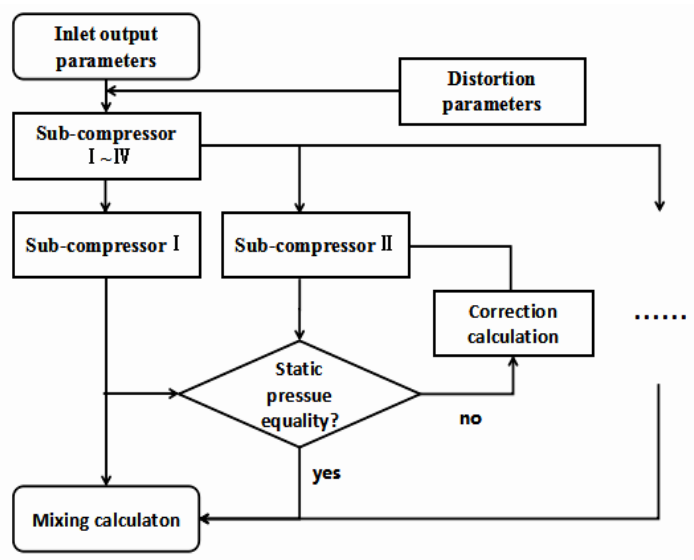

Figure 8. Algorithm of sub-compressor

\subsection{Stability index}

Conversion speed surge margin (SM) of compressor was chosen to be stability index in this paper. According to the fourth essential characteristic of the parallel compressor theory, the minimum SM value of each sub-compressor was considered as the SM of the whole compressor. SM is defined below:

$$
S M=\frac{\pi_{C, s} / W_{c o r, s}-\pi_{C, o} / W_{c o r, o}}{\pi_{C, o} / W_{c o r, o}}
$$

where $\pi$ is pressure ratio; $W$ is mass flow; $C$ is compressor; subscript $s$ is surge boundary; subscript $o$ is operating point; subscript cor means conversion value under international standard atmosphere (ISA).

\section{Improved fuel supply plan with DFI}

According to the acceleration performance requirements of this turboshaft engine, the fuel supply plan should be designed for satisfying those requirements, as shown in Table 2:

Table 2. Acceleration performance requirements

\begin{tabular}{|c|c|}
\hline Parameters & Requirement \\
\hline Surge margin $(\mathrm{SM})$ & $\$ 5 \%$ \\
\hline Gas turbine inlet temperature (Tt41) & $\ngtr 1430 \mathrm{~K}$ \\
\hline $\begin{array}{c}\text { Relative rotational speed } \\
\text { acceleration of gas generator }(\mathrm{dN})\end{array}$ & $\ngtr 6 \% / \mathrm{s}^{2}$ \\
\hline
\end{tabular}

\subsection{Original fuel supply plan design}

Fuel flow ratio (Wf/Pt3) is a widely used parameter in aeroengine control system [10]. Power extraction method [11] was used to design original fuel supply plan, as shown in Figure 9.

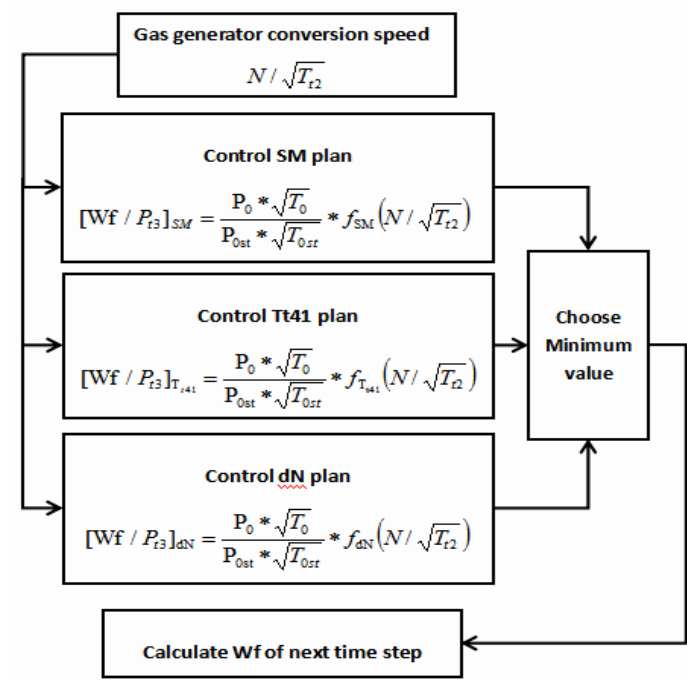

Figure 9. Original fuel supply plan

\subsection{Distortion factor Item method}

Distortion level coefficients were introduced into the control SM plan but without distortion Sector angles, Seen from formula (4). The SM of each sub-compressor was not affected by distortion sector angles because distortion sector angles had no impact on inlet flow thermal parameters.

$$
\begin{gathered}
{[W f / P t 3]_{\mathrm{SM}}=\frac{P * \sqrt{T_{0}}}{P_{0 \mathrm{st}} * \sqrt{T_{0 s t}}} *} \\
f_{\mathrm{SM}}\left(N / \sqrt{T_{t 2}}, 1+D P, 1+D T\right)
\end{gathered}
$$

where subscript st is standard atmosphere.

The formula (5) was deduced by first order Taylor expansion and its high order items were neglected. The first item in bracket of the formula right side is original fuel supply plan. The second item and the third item are distortion factor items. According to the input signal of distortion level coefficients, the control SM plan can be adjusted adaptively by distortion factor items.

$$
[W f / P t 3]_{S M}=\frac{P_{0} * \sqrt{T_{0}}}{P_{0 \mathrm{st}} * \sqrt{T_{0 s t}}} *\left[\begin{array}{l}
f_{\mathrm{SM}}\left(N / \sqrt{T_{t 2}}, 1,1\right) \\
+\frac{\partial f_{\mathrm{SM}}}{\partial D P} * \mathrm{D} P \\
+\frac{\partial f_{\mathrm{SM}}}{\partial D T} * D T
\end{array}\right]
$$

\section{Results}

\subsection{Performance}

Compared with the engine performance in the same operating condition without inlet flow distortion, a steadystate example was simulated to indicate the influence of the inlet flow distortion on overall performance.

Known conditions are shown as followed:

Environment: ISA, $\mathrm{H}=0 \mathrm{~km}, \mathrm{Ma}=0$

Initial state: $\mathrm{N}=100 \%, \mathrm{~Np}=100 \%$ 
Distortion level coefficient: $\mathrm{DP}=-6 \%, \mathrm{DT}=4 \%$

Distortion Sector angle: $\theta_{\mathrm{DP}}=90^{\circ}, \theta_{\mathrm{DT}}=90^{\circ}, \theta_{\mathrm{DPT}}=90^{\circ}$

\subsubsection{Compressor operation analysis}

Figure 10 shows the positions of compressor's equivalent operating point (green circle) and the operating point (black circle) of the same operating condition under uniform inflow. The purple operating point of the subcompressor which encountered combination distortion was very close to the surge boundary.

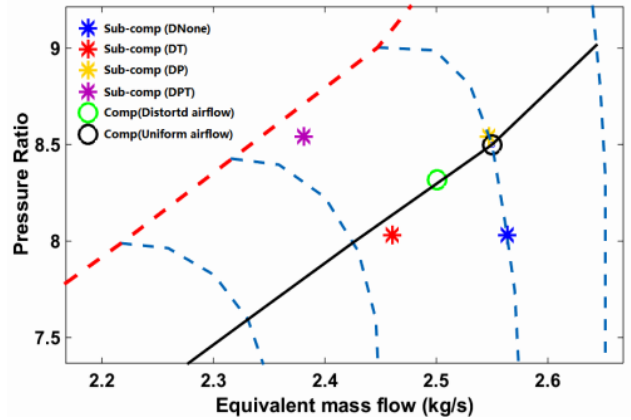

Figure 10. Positions of operating points

Inlet flow distortion led to drop of boosting capability and flow capacity. The SM had a great loss compared with uniform inflow (Table 3).

Table 3. Comparison of compressor performance

\begin{tabular}{|c|c|c|c|}
\hline Parameters & Uniform & Distortion & change $(\%)$ \\
\hline$\Delta \mathrm{SM}(\%)$ & 100 & 16.7 & -84.3 \\
\hline Pressure ratio & 8.5 & 8.277 & -2.62 \\
\hline Air inflow $(\mathrm{kg} / \mathrm{s})$ & 2.537 & 2.379 & -6.23 \\
\hline
\end{tabular}

\subsubsection{Overall performance}

Compared with uniform inflow, total pressure dropped and total temperature rose in each section (Table 4). The overall performance was worse with the decrease of power output and the increase of specific fuel consumption (SFC) (Table 5). Drop of gas total pressure suggest that the gas expansion capacity decreased so that less gas thermal energy converted into mechanical energy in turbine. The increase of exhaust outflow static temperature suggest that the exhaust loss increased.

Table 4. Main section parameters

\begin{tabular}{|c|c|c|c|c|}
\hline \multicolumn{2}{|c|}{$\begin{array}{c}\text { Section } \\
\text { Parameters }\end{array}$} & Uniform & Distortion & $\begin{array}{c}\text { Change } \\
(\%)\end{array}$ \\
\hline \multirow{2}{*}{3} & $\mathrm{Pt}(\mathrm{kpa})$ & 857.0 & 809.7 & -5.52 \\
\cline { 2 - 5 } & $\mathrm{Tt}(\mathrm{K})$ & 593.9 & 602.0 & +1.36 \\
\hline \multirow{2}{*}{4} & $\mathrm{Pt}(\mathrm{kpa})$ & 831.2 & 785.4 & -5.51 \\
\cline { 2 - 5 } & $\mathrm{Tt}(\mathrm{K})$ & 1427.1 & 1447.3 & +1.42 \\
\hline \multirow{2}{*}{5} & $\mathrm{Pt}(\mathrm{kpa})$ & 289.1 & 273.3 & -5.47 \\
\cline { 2 - 5 } & $\mathrm{Tt}(\mathrm{K})$ & 1142.5 & 1160.5 & +1.58 \\
\hline \multirow{2}{*}{6} & $\mathrm{Pt}(\mathrm{kpa})$ & 106.4 & 105.8 & -0.56 \\
\cline { 2 - 5 } & $\mathrm{Tt}(\mathrm{K})$ & 920.7 & 947.2 & +2.88 \\
\hline \multirow{2}{*}{9} & $\mathrm{Pt}(\mathrm{kpa})$ & 103.5 & 103.3 & -0.19 \\
\cline { 2 - 5 } & $\mathrm{Ts}(\mathrm{K})$ & 915.7 & 942.6 & +2.94 \\
\hline
\end{tabular}

Table 5. Overall performance parameters

\begin{tabular}{|c|c|c|c|}
\hline Parameters & Uniform & Distortion & $\begin{array}{c}\text { Change } \\
(\mathbf{\%})\end{array}$ \\
\hline $\mathrm{T}_{\mathrm{t} 41}(\mathrm{~K})$ & 1405 & 1425 & +1.42 \\
\hline$\pi_{\mathrm{GT}}$ & 2.875 & 2.873 & -0.07 \\
\hline$\eta_{\mathrm{GT}}$ & 0.852 & 0.849 & -0.35 \\
\hline $\mathrm{T}_{\mathrm{t} 51}(\mathrm{~K})$ & 1137 & 1155 & +1.58 \\
\hline$\pi_{\mathrm{PT}}$ & 2.672 & 2.531 & -5.28 \\
\hline$\eta_{\mathrm{PT}}$ & 0.893 & 0.890 & -0.34 \\
\hline $\mathrm{P}_{\mathrm{PT}}(\mathrm{kw})$ & 643.0 & 581.5 & -9.57 \\
\hline $\begin{array}{c}\mathrm{SFC} \\
(\mathrm{kg} /(\mathrm{h} * \mathrm{kw}))\end{array}$ & 0.3266 & 0.3450 & +5.63 \\
\hline \multicolumn{2}{|c|}{} & \multicolumn{2}{|c}{} \\
\hline
\end{tabular}

\subsection{Dynamic response}

A transition-state example was simulated to indicate the dynamic respond of the engine supposed that it encountered inlet flow distortion in flight.

Known conditions are shown as followed:

Environment: ISA, $\mathrm{H}=0.5 \mathrm{~km}, \mathrm{Ma}=0.3$

Initial state: $\mathrm{N}=100 \%, \mathrm{~Np}=100 \%$

Control strategy: kept Wf and Np constant

Distortion level coefficient: seen from Figure 11

Distortion Sector angle: $\theta_{\mathrm{DP}}=90^{\circ}, \theta_{\mathrm{DT}}=90^{\circ}, \theta_{\mathrm{DPT}}=90^{\circ}$

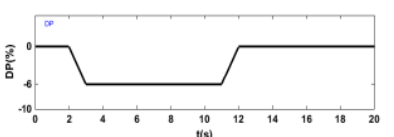

(a) DP

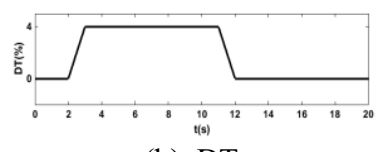

(b) DT
Figure 11. Distortion level coefficient input signal

Figure 12 shows the dynamic respond of gas generator. The reduction of gas turbine power was smaller than that of compressor power load caused by gas generator acceleration. When the inlet flow distortion disappeared gas generator decelerated to the initial state.

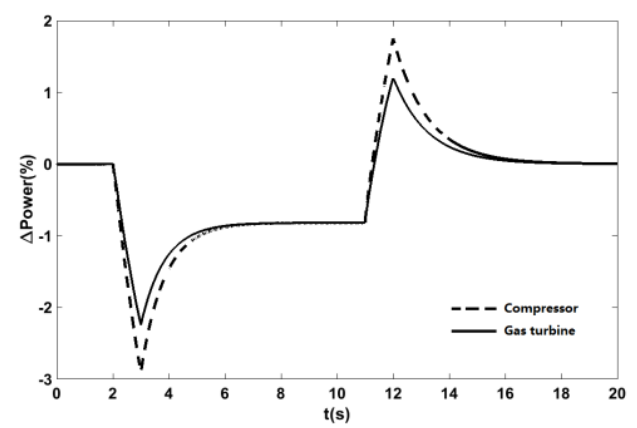

(a) Relative change of power and load

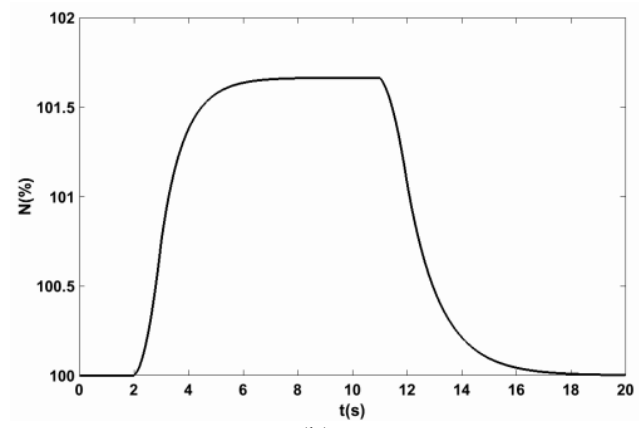

(b) $\mathrm{N}$

Figure 12. Dynamic respond of gas generator 
Figure 13 shows the dynamic respond of power output. The degree of gas mass flow decrease was much more than that of unit power increase so that power output dropped significantly.

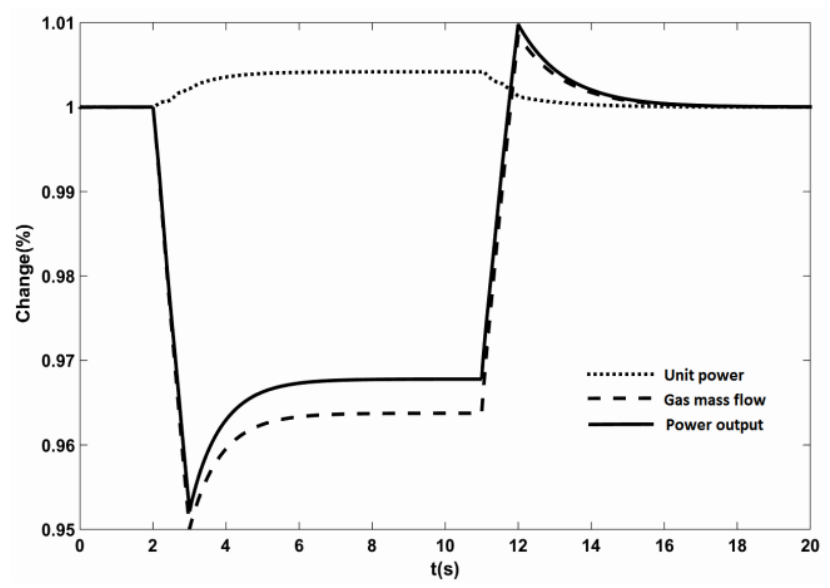

Figure 13. Dynamic respond of power output

\subsection{Above-idle acceleration with DFI method}

Several transition-state examples were simulated and shown below to demonstrate that DFI method has adaptability for surge-preventing acceleration from idle under different inlet flow distortion and has the advantage of environmental applicability. Wf was controlled by fuel supply plan with DFI.

\subsubsection{Adaptive surge-preventing}

Known conditions are shown as followed:

Environment: ISA, $\mathrm{H}=0, \mathrm{Ma}=0$

Initial state: $\mathrm{N}=75 \%, \mathrm{~Np}=100 \%$

1) Inlet flow distortion I : $\mathrm{DP}=-2 \%, \mathrm{DT}=1 \%$

2) Inlet flow distortion II : $\mathrm{DP}=-3 \%, \mathrm{DT}=2 \%$

3) Inlet flow distortion III: DP $=-6 \%, \mathrm{DT}=4 \%$

(The waveform of the signals were the same as Figure 10)

Distortion Sector angle: $\theta_{\mathrm{DP}}=90^{\circ}, \theta_{\mathrm{DT}}=90^{\circ}, \theta_{\mathrm{DPT}}=90^{\circ}$

Figure 14 shows the acceleration processes under three different inlet flow distortion.

1) Under inlet flow distortion I, Figure 14 (c) shows the engine surged with original fuel supply plan.

2) Under inlet flow distortion I, Wf increased more slowly for the SM requirement. The engine accelerated to expected operation condition directly but less slowly.

3) Under inlet flow distortion II, Wf stopped increasing temporarily and acceleration stopped. The engine accelerated to expected operation condition after the distortion disappeared.

4) Under inlet flow distortion III, Wf reduced and the engine decelerated. The engine accelerated to expected operation condition after the distortion disappeared.

Improved fuel supply plan with DFI could adaptively adjust fuel supply under different inlet flow distortion. The engine could maintain the expected surge margin and accelerated to the expected operating condition.

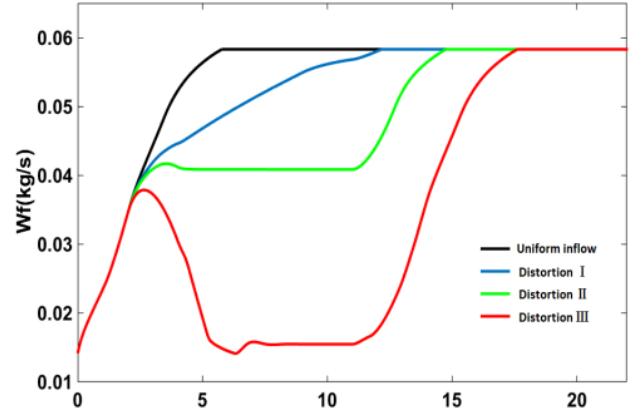

(a) $\mathrm{Wf}$

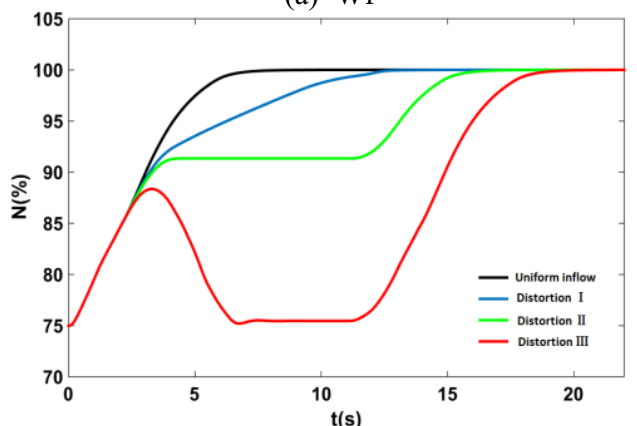

(b) $\mathrm{N}$

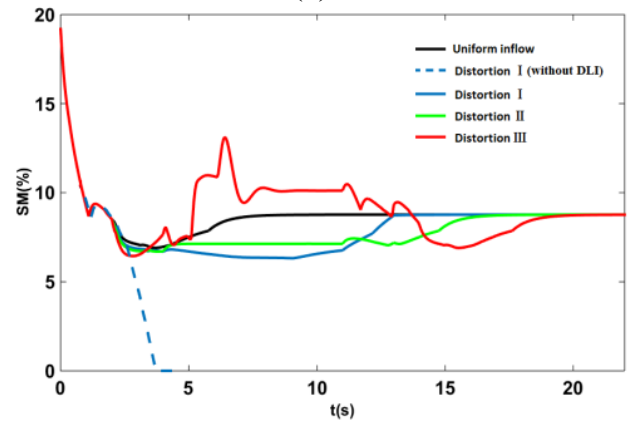

(c) $\mathrm{SM}$

Figure 14. Acceleration under different inlet flow distortion

\subsubsection{Environmental applicability}

1) Plateau environment

Known conditions are shown as followed: Environment: ISA, $\mathrm{H}=3 \mathrm{~km}, \mathrm{Ma}=0$

Initial state: $\mathrm{N}=75 \%, \mathrm{~Np}=100 \%$

Distortion level coefficient: DP $=-6 \%, \mathrm{DT}=4 \%$

(The waveform of the signal was the same as Figure 10) Distortion Sector angle: $\theta_{\mathrm{DP}}=90^{\circ}, \theta_{\mathrm{DT}}=90^{\circ}, \theta_{\mathrm{DPT}}=90^{\circ}$

Figure 15 shows the acceleration process in Plateau environment.

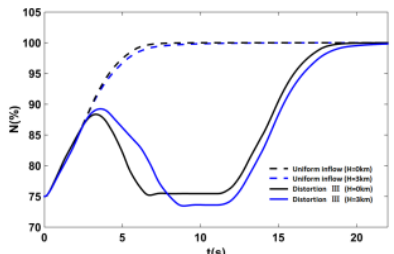

(a) $\mathrm{N}$

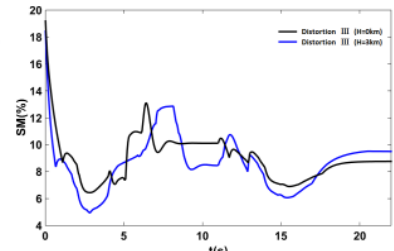

(b) $\mathrm{SM}$
Figure 15. Acceleration in different altitude

2) High/ Low temperature environment Known conditions are following below: Environment: $\mathrm{H}=0 \mathrm{~km}, \mathrm{Ma}=0, \mathrm{~T}_{\mathrm{amb}}=-30^{\circ} \mathrm{C} \& 50^{\circ} \mathrm{C}$ Initial state: $\mathrm{N}=75 \%, \mathrm{~Np}=100 \%$ Distortion level coefficient: $\mathrm{DP}=-6 \%, \mathrm{DT}=4 \%$ 
(The waveform of the signal was the same as Figure 10) Distortion Sector angle: $\theta_{\mathrm{DP}}=90^{\circ}, \theta_{\mathrm{DT}}=90^{\circ}, \theta_{\mathrm{DPT}}=90^{\circ}$

Figure 16 shows the acceleration process in high/ Low temperature environment.

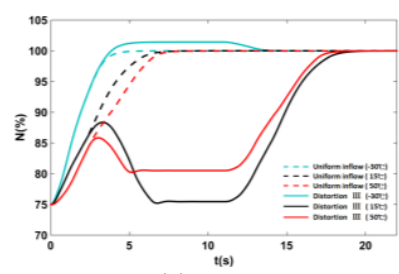

(a) $\mathrm{N}$

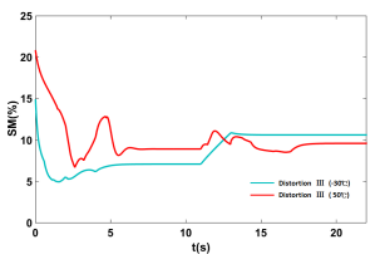

(b) SM
Figure 16. Acceleration in environment temperature

In extreme environment, the engine could still maintain the expected surge margin and accelerated to the expected operating conditions under inlet flow distortion.

\section{Conclusion}

The parallel compressor theory was applied to analyze inlet flow distortion influence on performance and dynamic respond of turboshaft engine. Acceleration was simulated with improved fuel supply plan under the condition of inlet flow distortion. The following conclusions were drawn from the analysis of the numerical simulation results:

1. Under condition of keeping rotor physical speed constant, inlet flow distortion weaken the flow capacity and boosting capacity of turbocharging system. Drop of total pressure weaken the energy conversion in turbine and leads to increase of exhaust loss. Surge margin has a great loss under inlet flow distortion so that the engine is more vulnerable to surge.

2. When fuel system supply constant fuel to the aeroengine without any intervention in flight, sudden encountering inlet flow distortion tips rotor power balance and makes rotor to accelerate. A rise in the gas total temperature of turbine inlet may lead to excessive thermal stress in turbine blades. The power output drops because the degree of working substance reduction is greater than that of unit power increase.

3. The Distortion Factor Item method presented here has adaptability for adjusting fuel supply when the engine encountering different inlet flow distortion. The Distortion Factor Item method is efficient for surge-preventing acceleration from idle under the circumstance of real-time distortion estimation, and its environmental applicability has been testified. This method could be beneficial to provide a solution to aeroengine control schedule when encountering flow distortion.

\section{Acknowledgment}

This research is funded by National Nature Science Foundation of China (NSFC) under Grants 51206005, and
Project MIIT. The author is thankful for the support from Collaborative Innovation Center of Advanced AeroEngine.

\section{References}

1. Mazzawy R S. Multiple Segment Parallel Compressor Model for Circumferential Flow Distortion[J]. Journal of Engineering for Gas Turbines \& Power, 99(2):288-296 (1977)

2. Chen J, Zheng $X$, Wang $C$, et al. Numerical Investigation of Influence of Radial Inlet Distortion on Compressor Performance in 2-Stage Turbocharging System[C]// ASME Turbo Expo 2014: Turbine Technical Conference and Exposition. American Society of Mechanical Engineers, (2014)

3. Yao J, Gorrell S E, Wadia A R. High-Fidelity Numerical Analysis of Per-Rev-Type Inlet Distortion Transfer in Multistage Fans: Part I-Simulations With Selected Blade Rows[J]. Journal of Turbomachinery, 132(4):457-467 (2010)

4. Yao J, Gorrell S E, Wadia A R. High-Fidelity Numerical Analysis of Per-Rev-Type Inlet Distortion Transfer in Multistage Fans: Part II-Entire Component Simulation and Investigation[J]. Journal of Turbomachinery, 132(4):457-467 (2010)

5. Sitaram N, Govardhan M, Murali K V. Effects of Inlet Pressure Distortion on the Performance and Flow Field of a Centrifugal Compressor at OffDesign Conditions[C]// ASME 2012 Gas Turbine India Conference. 35-50 (2012)

6. Orme J, Delaat J, Southwick R, et al. Development and testing of a High Stability Engine Control (HISTEC) system[J]. (2013)

7. Mink G, Behbahani A. The AFRL ICF Generic Gas Turbine Engine Model[C]// AIAA/ASME/SAE/ASEE Joint Propulsion Conference \& Exhibit. (2013)

8. Cousins W T, Davis M W, Cousins W $\mathrm{T}$, et al. Evaluating Complex Inlet Distortion With a Parallel Compressor Model: Part 1-Concepts, Theory, Extensions, and Limitations[C]// ASME 2011 Turbo Expo: Turbine Technical Conference and Exposition. 55-67 (2011)

9. Brennan B. Effect of a sinusoidal three-lobe total pressure distortion on a transonic compressor : distortion propagation, compressor performance, and blade passage events [D]. Massachusetts: Massachusetts Institute of Technology, Department of Aeronautics and Astronautics. 145-164 (2002)

10. Link C. Jaw, Jack D. Mattingly. Aircraft engine controls design, system, analysis, and health monitoring[M]. Aviation Industry Press, (2011)

11. CHEN Y C, XU S Y.Power extraction method of designing starting control strategy for turbofan engine $[\mathrm{J}]$. Journal of Propulsion Technology, 30(5):604-609 (2009) 